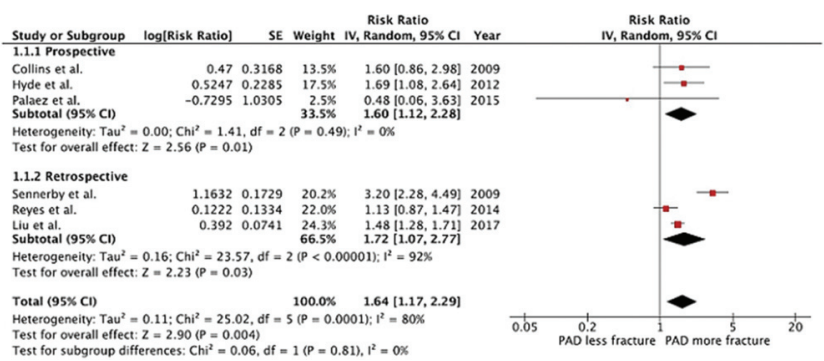

Conclusions: In summary, this study demonstrated a significantly increased risk

of incident hip fracture among patients with PAD compared with individuals without PAD.

Disclosure of Interest: None declared

DOI: 10.1136/annrheumdis-2018-eular.4739

\section{OP0064 GENERAL BONE LOSS IN PATIENTS WITH EROSIVE AND NON-EROSIVE HAND OSTEOARTHRITIS DURING THREE YEARS}

O. Ruzickova, K. Pavelka, L. Senolt, O. Sleglova. revmatology, Institute of revmatology, Prague 2, Czech Republic

Background: Hand osteoarthritis $(\mathrm{OA})$ and its more severe subset erosive hand $\mathrm{OA}$ are common causes of pain and morbidity. Some metabolic factors were suggested to be implicated in erosive disease. Few studies investigated differences in systemic bone loss between erosive and non-erosive hand OA.

Objectives: To compare the change of bone mineral density (BMD) between patients with erosive and non-erosive hand $O A$ in a longitudinal study after three years.

Methods: American College of Rheumatology (ACR) criteria were used to assess hand $O A$. Erosive hand $O A$ was defined by at least one erosive interphalangeal joint. All patients underwent clinical assessments of joint swelling and radiographs of both hands. DEXA examination of lumbar spine, total femur and femur neck was performed at baseline and after three years. Metabolic risk factors (body mass index, hypertension, diabetes, dyslipidaemia) were collected.

Results: Altogether, 144 patients (15 male) with symptomatic nodal HOA were included in this study and followed between ${ }^{\text {April } 2012}$ and January 2018. Out of these patients, 82 had erosive disease after three years. The disease duration $(p<0.01)$ was significantly higher in patients with erosive compared with non-erosive disease.

Most patients took symptomatic slow acting drugs (SYSADOA) twice a year, nonsteroidal anti-inflammatory drugs (NSAIDs) and analgesics on demand.

Baseline population characteristics did not differ between both groups. Osteoporosis (T-score $<-2.5 \mathrm{SD}$ ) was diagnosed in $12.5 \%$ (9/72) of patients with erosive hand $\mathrm{OA}$ and in $8.06 \%(5 / 57)$ of patients with non-erosive hand OA. Although BMD did not significantly differ between the groups (BMD of lumbar spine 1,05 g/ cm2 vs $1,13 \mathrm{~g} / \mathrm{cm} 2, \mathrm{p}<0.05$, total femur $0,90 \mathrm{~g} / \mathrm{cm} 2$ vs $0,97 \mathrm{~g} / \mathrm{cm} 2, \mathrm{p}<0.01$ and femur neck $0,86 \mathrm{~g} / \mathrm{cm} 2$ vs $0,91, \mathrm{p}<0.05)$, T-scores of lumbar spine $(-0.96$ vs $-0,41 \mathrm{SD}, \mathrm{p}<0.05)$, total femur ( -0.69 vs.

$-0,33 S D, p<0.05)$ and femur neck $(-1,14$ vs $-0,88 \mathrm{SD}, \mathrm{p}<0.05)$ were significantly lower in patients with erosive compared with non-erosive disease.

After three years, the decrease in T- score of lumbar spine was significantly higher in erosive hand OA compare to non-erosive disease $(-3,66 \%$ vs $15,52 \%$, $\mathrm{p}<0.01)$, also the decrease of $\mathrm{T}$-score in total femur was significantly higher in erosive hand OA compare to non-erosive disease $(-4,29 \%$ vs $7,68 \%, p<0.05)$.

The decrease of bone mineral density was also significantly higher in patients with erosive hand OA after three years. The decrease of BMD of lumbar spine was significantly higher in erosive hand $\mathrm{OA}$ after three years compare to non-erosive disease $(-3,30 \%$ vs $1,06 \%, p<0,05)$, the decrease of BMD in femur neck was significantly higher in erosive hand $\mathrm{OA}$ after three years compare to non-erosive disease $(-3,2 \%$ vs $0,02 \%, p<0,05)$, the decrease of BMD total femur neck was significantly higher in erosive hand $\mathrm{OA}$ after three years compare to non-erosive disease $(-1,58 \%$ vs $0,82 \%, p<0,05)$.

Conclusions: These results suggest that patients with erosive hand $\mathrm{OA}$ are at higher risk for development of deep general bone loss.

Acknowledgement: This work was supported by the project MHCR No. 023728.

Disclosure of Interest: None declared

DOI: 10.1136/annrheumdis-2018-eular.6324

\section{OP0065 \\ OSTEOPOROSIS AND VERTEBRAL FRACTURESARE ASSOCIATED WITH DISEASE ACTIVITY AND RADIOGRAPHIC DAMAGE IN PATIENTS WITH AXIAL SPONDYLOARTHRITIS}

C. Romera-Lopez ${ }^{1}$, C. Fernández-Carballido ${ }^{2}$, M. Martínez-Vidal ${ }^{3}$, T. Pedraz ${ }^{2}$. ${ }^{1}$ Reumatología, Hospital Vinalopo, Elche, Alicante; ${ }^{2}$ Reumatología, Hospital General Univeritario de Elda, Alicante, Elda, Alicante; ${ }^{3}$ Reumatología, Hospital general Universitario de Alicante, Alicante, Spain

Background: Osteoporosis (OP) and vertebral fractures (VF) are common comorbidities of axial Spondyloarthritis (axSpA) with deleterious effects for the physical function of the patients.

Objectives: To evaluate the relationship between disease activity and radiographic damage and bone mineral density (BMD), $25(\mathrm{OH})$ vitamin $D$ levels and VF in patients with axSpA (ASAS Criteria).

Methods: Cross-sectional study. Activity variables: Bath Ankylosing Spondylitis Disease Activity Index (BASDAI) and Ankylosing Spondylitis Disease Activity Score (ASDAS); ESR and CRP. Vitamin D insufficiency if $<30 \mathrm{ng} / \mathrm{mL}$. Lumbar Spine (LS) and femoral neck (FN) Dual X-ray absorptiometry (DXA) performed. Evaluation of VF with semiquantitative method (Genant) in thoracolumbar X-rays. Bivariate analysis to evaluate the associations with the presence of $\mathrm{OP}$ and/or VF, then binary and multiple logistic regression models, by using SPSS (v23); p values $<0.05$ considered significant.

Results: We studied 206 patients (62 women/144 men); 86\% AS/14\% nr-axSpA and associated peripheral involvement in $42 \%$. Mean \pm standard deviation (SD) values: age 52 \pm 14 ; activity (BASDAI 3.6 \pm 2.2 , ASDAS-CRP 2.2 \pm 0.95 , ASDASESR 2.5 \pm 0.99 , CRP $4.97 \pm 8.97 \mathrm{mg} / \mathrm{L}$, ESR $18.2 \pm 14,8 \mathrm{~mm}$ ); physical function (BASFI 3.3 \pm 2.7 ); radiographic damage: $\mathrm{mSASSS}$ total $20.46 \pm 19.14$, lumbar $10.41 \pm 9.89$ and cervical $10.05 \pm 10.78 ; 25(\mathrm{OH})$ vitD $19.83 \pm 9.25 \mathrm{ng} / \mathrm{mL}, 85.7 \%$ of the patients had insufficiency. Low LS BMD in $25.7 \%$ (z-score) and $28.9 \%$ (tscore) and low FN BMD in $45.2 \%(\mathrm{z})$ and $28.9 \%(\mathrm{t})$ of the patients. OP prevalence in LS 3.2\%(z)/6.9\%(t) and in FN 9.1\% (z)/13.4\% (t). Morphometric VF were identified in $34 \%$ of the patients.

Bivariate analysis: ESR, ASDAS-ESR, age, male sex, low $25(\mathrm{OH})$ vitD levels and the mSASSS were associated with low FN BMD. Multivariate models confirmed the association between disease activity (ASDAS-ESR) [OR 3.32 (95\% Cl: 2.35 to 4.55); $p=0.016$ ], 25(OH)D [OR 0.95 (95\% Cl: 0.86 to 0.98); $p=0.029$ ] and low FN BMD (z score).

An association was confirmed between CRP [OR 2.34 (95\% Cl: 1.10 to 4.98$)$; $\mathrm{p}=0.027$ ], radiographic damage [lumbar mSASSS OR 1.06 (95\% Cl: 1.03 to 1.10$)$ $p=0.001$ ], high LS BMD [OR 296 (95\% Cl: 5.07 to 12258); $p=0.006$ ] and low FN BMD [OR 0.11 (95\% Cl: 0.03 to 0.12); $p=0.000$ ] and the presence of $\mathrm{FF}$.

Abstract OP0065 - Table 1. Differences between patients without or with VF

\begin{tabular}{lccc}
\hline & $\begin{array}{c}\text { Without } \\
\text { VF }\end{array}$ & With VF & $\mathrm{p}$ value \\
\hline CRP $(\mathrm{mg} / \mathrm{L})$ & $5.10 \pm 1.6$ & $9.51 \pm 2.1$ & $\mathrm{p}=0.003$ \\
ESR $(\mathrm{mm} / \mathrm{h})$ & $15.87 \pm 4.8$ & $23.12 \pm 6.2$ & $\mathrm{p}=0.002$ \\
$25 \mathrm{OHvitD}(\mathrm{ng} /$ & $20.80 \pm 4.6$ & $18.04 \pm 3.7$ & $\mathrm{p}=0.049$ \\
$\mathrm{~mL})$ & & & \\
cervical mSASSS & $8.02 \pm 2.5$ & $13.11 \pm 4.8$ & $\mathrm{p}=0.002$ \\
lumbar mSASSS & $8.93 \pm 3.7$ & $12.36 \pm 6.5$ & $\mathrm{p}=0.000$ \\
total mSASSS & $17.66 \pm 7.3$ & 27.13 & $\mathrm{p}=0.000$ \\
& & \pm 10.7 & \\
LS BMD & 1.090 & 1.191 & $\mathrm{p}=0.002$ \\
& \pm 0.09 & \pm 0.13 & \\
FN BMD & 0.912 & 0.773 & $\mathrm{p}=0.000$ \\
& \pm 0.11 & \pm 0.18 & \\
\hline
\end{tabular}

Conclusions: In patients with axSpA, low FN BMD is associated with disease activity and vitamin D insufficiency and VF are associated with CRP and low hip bone mass. Furthermore, the presence of radiographic damage, even when 'falsely' increases LS BMD, is associated with the presence of fractures.

\section{REFERENCE:}

[1] Van der Heide, et al. 2016 update of the ASAS-EULAR management recommendations of axial SpA. Ann Rheum Dis 2017 Jun;76(6):978-991.

Disclosure of Interest: None declared DOI: 10.1136/annrheumdis-2018-eular.2491 